\title{
Effects of the vat pasteurization process and refrigerated storage on the bovine milk metabolome
}

\author{
Dan Zhu, ${ }^{1,2}$ ๑ Biniam Kebede, ${ }^{3} \odot$ Gang Chen, ${ }^{2}$ Kiri McComb, ${ }^{1} \odot$ and Russell Frew ${ }^{1 *}$ (]) \\ ${ }^{1}$ Department of Chemistry, University of Otago, Dunedin, New Zealand 9016 \\ ${ }^{2}$ Key Laboratory of Agro-Product Quality and Safety, Institute of Quality Standards and Testing Technology for Agro-Products, \\ Chinese Academy of Agricultural Sciences (CAAS), Beijing, China 100081 \\ ${ }^{3}$ Department of Food Science, University of Otago, Dunedin, New Zealand 9016
}

\begin{abstract}
This study is the first to investigate the evolution of cow milk metabolites throughout the vat pasteurization process and storage using untargeted metabolomics based on a multiplatform approach. Nuclear magnetic resonance and ultraperformance liquid chromatography-quadrupole time-of-flight mass spectrometry were used for fingerprinting water-soluble nutritional compounds, and headspace gas chromatography-mass spectrometry was used to fingerprint the volatile organic compounds. This study demonstrated that vat pasteurization was an efficient and mild means of milk preservation resulting in only minor changes to the metabolites. The pasteurized milk samples exhibited a stable metabolome during the first $8 \mathrm{~d}$ of refrigerated storage. However, at the latter stage of storage, the concentrations of pantothenic acid and butyrylcarnitine decreased, whereas some fatty acids, organic acids, $\alpha$-AA, peptides, and ketones increased. These selected metabolites that changed during milk storage could be used as potential biomarkers to track the storage conditions of pasteurized cow milk.
\end{abstract}

Key words: pasteurization process, shelf-life study, untargeted metabolomics

\section{INTRODUCTION}

Milk, as a food consumed daily, provides essential nutrients. Although some possible benefits of raw milk consumption have been proposed, significant concerns still exist with respect to quality management and public health (Lucey, 2015). Raw milk is a highly perishable commodity and has a very short shelf life, as raw milk serves as an excellent medium for bacteria growth (Borad et al., 2017). Thus, raw milk is hard to preserve

Received August 28, 2019.

Accepted November 19, 2019.

*Corresponding author: russell.frew@otago.ac.nz or transport long distances. To maintain milk stability and increase shelf life, milk processing is always used to prevent diseases caused by the pathogens or spoilage microorganisms present in milk (Meunier-Goddik and Sandra, 2011).

To preserve the nutritional value of milk, different types of low-temperature pasteurization are commonly used onsite, such as vat pasteurization or low temperature, long time pasteurization $\left(63^{\circ} \mathrm{C}\right.$ for $\left.30 \mathrm{~min}\right)$, HTST pasteurization $\left(72^{\circ} \mathrm{C}\right.$ for $\left.15 \mathrm{~s}\right)$, and higher heat, shorter time pasteurization $\left(>89^{\circ} \mathrm{C}\right.$ for $<1.0 \mathrm{~s}$; Meunier-Goddik and Sandra, 2011; Watts, 2016). The shelf life of the pasteurized milk is reported to be 7 to $28 \mathrm{~d}$ under refrigeration, depending on the raw milk quality and postpasteurization contamination (Martin et al., 2018). Compared with HTST and higher heat, shorter time pasteurization, vat pasteurization is slow and inefficient (Meunier-Goddik and Sandra, 2016). However, vatpasteurized milk tastes fresher, thus providing a taste similar to raw milk without the health concerns. It is reported that vat-pasteurized milk has become popular again as more small dairy processors are using it to appeal to customers seeking a more "farm-fresh" milk (Berkeley Wellness, 2014). In addition, vat pasteurization is used extensively in the dairy industry as a means of preparing milk in the processing of ice cream, cheese, yogurt, and other common food products (Rankin et al., 2017). The shelf life of pasteurized milk is usually determined by microbial analysis or sensory analysis (Meunier-Goddik and Sandra, 2011). The SPC of raw milk samples is considered acceptable when below $50,000 \mathrm{cfu} / \mathrm{mL}$, whereas the SPC of pasteurized milk should be $<20,000 \mathrm{cfu} / \mathrm{mL}$ (Gandy et al., 2008).

Milk is known to oxidize during processing and storage, resulting in deterioration of flavor and nutritional value. Thus, the composition and nutritional properties in milk may be altered due to heat-related reactions. Such changes were reported to be caused by lactose degradation, protein denaturation, or lipid hydrolysis (Sakkas et al., 2014). Although most of the physicochemical properties could be preserved during 
low-temperature pasteurization, some compounds were observed to have changed after pasteurization or during storage. It was reported that the levels of the detected volatile organic compounds (VOC) in pasteurized milk were related to the temperature $\left(77-85^{\circ} \mathrm{C}\right)$ used for processing the milk. The VOC from pasteurized milk processed under different conditions, however, showed similar trends during the storage period (0-19 d; Gandy et al., 2008). Rashid et al. (2019) investigated the off-flavoring VOC of pasteurized milk under different storage conditions and found that the levels of acetone, butanone, pentanal, and ethanol increased significantly during storage. In addition, some studies found that the vitamin contents were affected by pasteurization; these results are summarized in Macdonald et al. (2011). Generally, the vitamin content is lower in pasteurized milk; this is especially true for vitamins $\mathrm{B}_{2}$ and E. Substantial loss of labile vitamins, such as vitamins $\mathrm{A}$ and $\mathrm{D}$, was observed due to processing and subsequent storage conditions (Cappozzo et al., 2015). In contrast, the total concentration of SFA and UFA remained stable and the total CLA content increased in pasteurized cow milk $\left(72^{\circ} \mathrm{C}\right.$ for $30 \mathrm{~s}$; Rodríguez-Alcalá et al., 2014). However, in goat milk, the total SFA content was found to have increased and the total UFA content decreased after pasteurization at $65^{\circ} \mathrm{C}$ for 30 min (Wang et al., 2016).

Metabolomics, or metabonomics, represents the "omics" study of the chemical processes involving metabolites using large-scale and high-throughput techniques (Nicholson et al., 1999). The metabolites include a range of exogenous and endogenous chemical compounds with molecular weight less than 1,500 Da, such as AA, organic acids, vitamins, carbohydrates, fatty acids, nucleic acids, peptides, lipids, alkaloids, and any other compounds detected from the organism (Wishart, 2008). In the last 2 decades, metabolomics studies have been applied in food science research, including food quality, food safety, and traceability (Wishart, 2008; Kim et al., 2016). However, understanding of the effect of vat pasteurization and subsequent storage on milk metabolites is still limited. Zhang et al. (2018) developed a metabolomics method for distinguishing raw milk, pasteurized milk, and UHT milk based on ultraperformance liquid chromatography-quadrupole time-of-flight MS (UPLC-QToF/MS). However, only the biomarkers to differentiate UHT milk from raw milk and pasteurized milk were identified (7 oxylipids and 1 phospholipid) and listed in their study. Additionally, the storage stability of the metabolites in the pasteurized milk under refrigerated conditions has not yet been reported.

In this study, the effect of the vat pasteurization process and subsequent refrigerated storage on milk metabolites in the liquid and volatile fractions was measured. ${ }^{1} \mathrm{H}$ nuclear magnetic resonance (NMR) and UPLC-QToF/MS techniques were integrated to detect a broad range of milk metabolites in the liquid fraction. Additionally, the VOC were detected using a headspace GC-MS fingerprinting method. This study provides a comprehensive understanding of milk metabolomics according to the pasteurization process and shelf-life storage. Moreover, once identified, the potential biomarkers could be used to help build a new approach to predict the shelf life of pasteurized milk.

\section{MATERIALS AND METHODS}

\section{Reagents}

The organic solvents, methanol and acetonitrile, were HPLC grade and purchased from Fisher Scientific (Hampton, NH). Sodium phosphate monobasic $\left(\mathrm{NaH}_{2} \mathrm{PO}_{4}\right)$, disodium hydrogen phosphate $\left(\mathrm{Na}_{2} \mathrm{HPO}_{4}\right)$, sodium 3-(trimethylsilyl) propionate-2,2,3,3-d4 (D, $99 \%)$, and deuterium oxide $\left(\mathbf{D}_{2} \mathbf{O} ; \mathrm{D}, 99.9 \%\right)$ were purchased from Sigma-Aldrich (St. Louis, MO). Milli-Q water $\left(18.2 \mathrm{M} \Omega / \mathrm{cm}\right.$ at $25^{\circ} \mathrm{C}$; Milli-Q Integral Water Purification System, Millipore Corporation, Bedford, MA) was used for all solutions. Phosphate buffer $(0.1 \mathrm{M}, \mathrm{pH}=7.4)$ was prepared by adding $0.269 \mathrm{~g}$ of $\mathrm{NaH}_{2} \mathrm{PO}_{4}$ and $1.09 \mathrm{~g}$ of $\mathrm{Na}_{2} \mathrm{HPO}_{4}$ to $100 \mathrm{~mL}$ of $\mathrm{D}_{2} \mathrm{O}$.

\section{Sample Collection}

Both the raw milk and the milk that was vat pasteurized after low temperature, long time $\left(63-64.5^{\circ} \mathrm{C}\right.$ for 30 min) processing were collected from Holy Cow Farm (Dunedin, New Zealand); the milk had approximately $4.4 \%$ fat content. Raw milk and pasteurized milk samples were taken from the homogeneous bulk tank before and after processing. Samples were collected in 500-mL high-density polyethylene wide-mouthed bottles (Nalgene, Rochester, NY). All the collected milk samples were kept in the container with ice packs and delivered to the laboratory within $4 \mathrm{~h}$. Sampling was conducted over 6 consecutive days to ensure the consistency of the samples. One bottle of raw milk and 7 bottles of the pasteurized milk from the same batch of raw milk were collected each day.

For studying the milk metabolite changes during refrigerated storage of the pasteurized milk, the samples were stored at $4^{\circ} \mathrm{C}$ and measured on $\mathrm{d} 0,2,4,8$, and 12 according to the microbial test (see Supplemental Table S1, https://doi.org/10.3168/jds.2019-17512). A preliminary experiment showed that the effect of freeze-drying on milk metabolites was minimal as most of the fold changes of the selected metabolites were 
within a factor of 2. Moreover, the freeze-dried milk powder, stored at $-20^{\circ} \mathrm{C}$, showed excellent metabolome stability for at least $224 \mathrm{~d}$ (data not shown). Therefore, for ${ }^{1} \mathrm{H}-\mathrm{NMR}$ and UPLC-QToF/MS measurements, the samples were initially kept in the freezer $\left(-20^{\circ} \mathrm{C}\right)$ and underwent freeze-drying within 2 wk. For detection of the volatile compounds, the liquid milk was quickly frozen under liquid nitrogen and stored under $-80^{\circ} \mathrm{C}$.

\section{Sample Preparation}

Sample Preparation for ${ }^{1} H-N M R$ and $U P L C$ $Q T o F / M S$. First, $1 \mathrm{~g}$ of the freeze-dried milk was redissolved in $4 \mathrm{~mL}$ of Milli-Q water and centrifuged at $8,225 \times g$ for $30 \mathrm{~min}\left(4^{\circ} \mathrm{C}\right)$ to remove fats and some impurities. The supernatant was then collected, and 1.0 $\mathrm{mL}$ was transferred to a new centrifuge tube. For NMR detection, $2.0 \mathrm{~mL}$ of methanol was added to the skim milk, vortexed for $10 \mathrm{~min}$, and centrifuged at $8,225 \times$ $g$ for $15 \min \left(4^{\circ} \mathrm{C}\right)$. The polar phase was collected and dried under nitrogen. The dried samples were redissolved with $700 \mu \mathrm{L}$ of $\mathrm{D}_{2} \mathrm{O}[0.1 M$ phosphate buffer, $\mathrm{pH}=7.4 ; 2.5 \mathrm{mmol} / \mathrm{L}$ sodium 3-(trimethylsilyl) propionate- $2,2,3,3-\mathrm{d} 4$ ] , and $600 \mu \mathrm{L}$ of liquid was taken to the NMR tube. For UPLC-QToF/MS detection, $2.0 \mathrm{~mL}$ of acetonitrile was added to the skim milk, vortexed for $10 \mathrm{~min}$, and centrifuged at $14,805 \times g$ for $10 \mathrm{~min}\left(4^{\circ} \mathrm{C}\right)$. The polar phase was collected and filtered through a $0.22-\mu \mathrm{m}$ filter membrane before the LC-MS analyses. All the sample preparation was performed in triplicate.

Sample Preparation for the Headspace GC-MS Analysis. The samples preserved under $-80^{\circ} \mathrm{C}$ were defrosted at $25^{\circ} \mathrm{C}$ in a water bath before analysis. Ten milliliters of the milk sample was immediately transferred to a $20-\mathrm{mL}$ glass sample vial. Vials were sealed using crimp-top caps with polytetrafluoroethylene/ silicone headspace septum. After preliminary trials, the mixtures were incubated at $50^{\circ} \mathrm{C}$ for $40 \mathrm{~min}$ with $500 \mathrm{rpm}$ vibration. Solid-phase microextraction using a 50/30- $\mu \mathrm{m}$ divinylbenzene/carboxen/polydimethylsiloxane fiber (Yi et al., 2016) was used to extract the volatile compounds from the headspace. The headspace-solid-phase microextraction was performed on a milk sample for $40 \mathrm{~min}$ at $45^{\circ} \mathrm{C}$ to allow adsorption of volatiles. Everything used was clean, and samples were not left on the autosampler longer than $7 \mathrm{~h}$ to avoid microbial growth.

\section{Instrumentation}

NMR Spectroscopy. High-resolution ${ }^{1} \mathrm{H}-\mathrm{NMR}$ spectra of milk extracts were obtained on a Varian
(Palo Alto, CA) 400 NMR spectrometer. The ${ }^{1} \mathrm{H}-\mathrm{NMR}$ spectra were acquired with $90^{\circ}$ pulse sequence, 2 -s relaxation delay, and 128 scan numbers.

UPLC-QToF/MS. Untargeted metabolomic profiles of the milk samples were carried out using UPLCQToF/MS 6600 (AB Sciex, Framingham, MA). The chromatographic separation was performed on a Zorbax Eclipse Plus C18 column (Agilent Technologies, Santa Clara, CA; $1.8 \mu \mathrm{m} \times 3.0 \mathrm{~mm} \times 150 \mathrm{~mm}$ at $\left.40^{\circ} \mathrm{C}\right)$. The MS/MS spectra were acquired via the informationdependent acquisition experiment based on preselected criteria. The specific conditions of the MS spectrometry are shown in Supplemental File S1 (https://doi.org/10 $.3168 /$ jds.2019-17512).

GC-MS Analysis. Gas chromatographic separations were performed with an Agilent Technologies 6890N GC system connected to an Agilent MSD 5975 VL. The Zebron ZB-Wax column $(60 \mathrm{~m} \times 0.32 \mathrm{~mm}$ i.d., $0.50 \mu \mathrm{m}$ film thickness; Phenomenex, Torrance, CA) was selected for this study. The specific conditions of the GC-MS are shown in Supplemental File S1.

\section{Data Preprocessing and Database Annotation}

Metabolomic Study. The NMR data were processed using Vnmrj 4.2 packaged with CRAFT software (Krishnamurthy, 2013), which converted time-domain data into frequency-amplitude data using Bayesian analysis. The UPLC-QToF/MS data set was extracted via MasterView and MultiQuant of AB Sciex. Confirmation of the identity of these compounds from both the NMR and MS techniques was achieved by referring to previous reports and databases, including the database from AB Sciex (Metabolite_HR-MS/MS_1.0), The Human Metabolome Database (HMDB; http:/ /www.hmdb.ca), and Metlin (http://metlin.scripps .edu). Retention time and accurate mass and mass spectrometric fragmentations were both considered for MS compound identification.

VOC Study. For the VOC, the "pure" component spectra were obtained by analyzing the GC-MS total ion chromatograms with Amdis version 2.72 (National Institute of Standards and Technology, Gaithersburg, MD). The deconvoluted spectra were then analyzed with Mass Profiler Professional (version 14.9.1; Agilent Technologies) for peak filtering and alignment (Yi et al., 2017). The identification of VOC was performed by comparing the compound's mass spectrum with the reference mass spectrum from the National Institute of Standards and Technology spectral library. For identification, a threshold match of $90 \%$ was taken into account. In addition, the rentention index of the compounds were calculated in relation to n-alkenes $\left(\mathrm{C}_{8}-\mathrm{C}_{22}\right)$ 
under the same operating conditions of the column and compared with that in the literature (Ott et al., 1997).

\section{Data Analysis}

Multivariate data analysis was carried out using $\mathrm{R}$ (version 3.5.3) for statistical computing (R Core Team, 2019). Unsupervised [principal components analysis (PCA)] and supervised [partial least squares discriminant analysis (PLS-DA) and partial least squares regression (PLSR)] methods were used to build the multivariate models. Specifically, PCA was performed to explore the data set for outliers as well as visualize clustering and trends among the samples. The PLSDA and PLSR methods were used to select and explain the possible metabolite differences as a function of storage. The numbers of principal components or latent variables $(\mathbf{L V})$ were selected according to the cumulative variance explained and root mean squared error; $\mathbf{R}^{2} \mathbf{X}$ and $\mathbf{R}^{2} \mathbf{Y}$ represent the cumulative modeled variation, and $\mathbf{Q}^{2}$ is an estimate of predictive model ability, calculated using a cross-validation procedure. The numbers of components were chosen considering the explained variances and root mean squared error values. The variable importance in projection (VIP) scores were calculated to measure the variable's importance and select the potential markers (metabolites significantly affected by the storage conditions). Univariate statistics were also exploited to investigate the potential variability of features. A Shapiro-Wilk test was used to test whether the data were normally distributed (Shapiro and Wilk, 1965), and then proper ANOVA was chosen to test whether there were significant differences among the samples stored at different conditions and for different days. Student's $t$-test and Wilcoxon rank-sum test (Mann-Whitney U test) were chosen for normal-distributed data and nonparametric data, respectively (Di Guida et al., 2016). Moreover, fold change was combined with the VIP values from the multivariate data analysis to filter the biomarkers changed upon the storage conditions.

\section{RESULTS AND DISCUSSION}

\section{Data Preprocessing}

Based on the ${ }^{1} \mathrm{H}-\mathrm{NMR}$ spectrum (Supplemental Figure S1, https://doi.org/10.3168/jds.2019-17512) and ${ }^{13} \mathrm{C}-\mathrm{NMR}$ spectrum, a total of 31 metabolites were identified. For the UPLC-QToF/MS data, 78 and 136 features were selected in positive and negative ion mode, respectively, after applying the preprocessing procedures (see Data Preprocessing and Database Annotation section). The extracted ion chromatogram under both the positive and negative modes of the UPLC-QToF/MS is shown in Supplemental Figure S2 (https://doi.org/10.3168/jds.2019-17512). For the VOC detected by GC-MS, 12 VOC were identified and are listed in Supplemental Table S2 (https://doi.org/10 $.3168 /$ jds.2019-17512).

\section{Effect of Pasteurization on Milk Metabolites}

Data sets from the ${ }^{1} \mathrm{H}-\mathrm{NMR}$, UPLC-QToF $/ \mathrm{MS}\left(\mathrm{ESI}^{+}\right.$ and $\mathrm{ESI}^{-} ; \mathbf{E S I}=$ electrospray ionization) and GC-MS were modeled using multivariate data analysis, including unsupervised PCA and supervised PLS-DA. Principal components analysis (using 2 principal components) was first applied to explore trends and classifications due to the pasteurization process. The $95 \%$ confidence ellipses were drawn to represent different groups. As illustrated in Supplemental Figure S3 (https://doi.org/ 10.3168/jds.2019-17512), a difference could be observed between the raw milk and pasteurized milk samples according to the measurements of metabolites by NMR or UPLC-QToF/MS and VOC acquired from GC-MS. To further investigate the sample classification due to the pasteurization process, PLS-DA was performed on each data set, and the scores plot (using the first $2 \mathrm{LV}$ ) is shown in Figure 1. All the models performed well according to the $R^{2} Y$ and $Q^{2}$ values calculated via a leave-one-out cross-validation method, which was used to describe the percentage of the variation explained by the model and the predictive ability of the model, respectively (Figure 1). The metabolites affected by the pasteurization process were selected according to their VIP scores (VIP >1.20) based on the PLS-DA model and fold changes before and after the processing. The instrumental variability of the untargeted analysis is approximately $30 \%$; hence, the metabolites with fold change values less than 1.30 were not considered. Therefore, the fold change thresholds were fixed at 2.0 for filtering the moderate impacted features caused by the pasteurization process, which would not be influenced by the instrument errors. The selected metabolites were summarized in Supplemental Table S3 (https://doi.org/10.3168/jds.2019-17512). Although on the score plots the milk samples after processing seem to be separated from the raw samples, most of the fold changes of the selected metabolites were within a factor of 2 . Hence, no metabolites could be selected according to the above criteria based on NMR data alone. Only 2 VOC were filtered out; the content of 2-nonanone increased and that of 2-butanone decreased after being pasteurized. In addition, a few of metabolites were screened out based on the LC-MS technique. Specifically, the concentrations of deoxyguanosine (268.1040 $\left.[\mathrm{M}+\mathrm{H}]^{+}\right)$, adenine $\left(136.0618[\mathrm{M}+\mathrm{H}]^{+}\right)$, and taurocholic 
acid $\left(514.2840[\mathrm{M}+\mathrm{H}]^{+}\right)$decreased, whereas the levels of arginylproline $\left(254.1614[\mathrm{M}+\mathrm{H}]^{+}\right), \quad$ 2-methylbutyroylcarnitine $\left(246.1705[\mathrm{M}+\mathrm{H}]^{+}\right)$, lysoPC $(482.3240$ $\left.[\mathrm{M}+\mathrm{H}]^{+}\right)$, and $N$-acetyl-D-glucosamine 1-phosphate $\left(300.0487[\mathrm{M}+\mathrm{H}]^{+}\right)$increased in the pasteurized milk. The lactose and free fatty acid contents detected in the pasteurized milk were changed very little compared with those in the raw milk, which was inconsistent with a previous report (Souza et al., 2015). Overall, most of the investigated metabolites were stable during the pasteurization process, and most of the VOC changed very little during processing. Therefore, the pasteurization condition applied in the present work can be considered mild, resulting in only minor metabolite changes in the liquid and volatile fractions.

\section{Effect of Refrigerated Storage on Milk Metabolites}

To investigate the influence of refrigerated storage $\left(4^{\circ} \mathrm{C}\right)$ on pasteurized milk, PCA and PLSR methods were used to analyze the data sets acquired from the multiplatform approaches. First, unsupervised PCA was explored on the data based on LC-MS, NMR, and GC-MS techniques. The corresponding score plots are shown in Supplemental Figure S4 (https://doi.org/10 $.3168 /$ jds.2019-17512) with the changing trend arrows inserted. As can be seen from the PCA score plots of the LC-MS and NMR metabolites, the pasteurized milk stored at $4^{\circ} \mathrm{C}$ did not show obvious changes until d 8 . For the VOC, a slight trend could be observed. However, the changes were not large, with most samples still clustered as they were previously. The PLSR model was applied with the aim of obtaining better insight into the changes during refrigerated storage. The PLSR model was also used to reveal which biomarkers were changing as a function of storage time. The score plots based on different data sets were illustrated in Figure 2 with the $R^{2} Y$ and $Q^{2}$ values acquired via the $k$-fold cross-validation $(\mathrm{k}=5)$ with $2 \mathrm{LV}$. As indicated in the PLSR score plots, the pasteurized milk samples re-
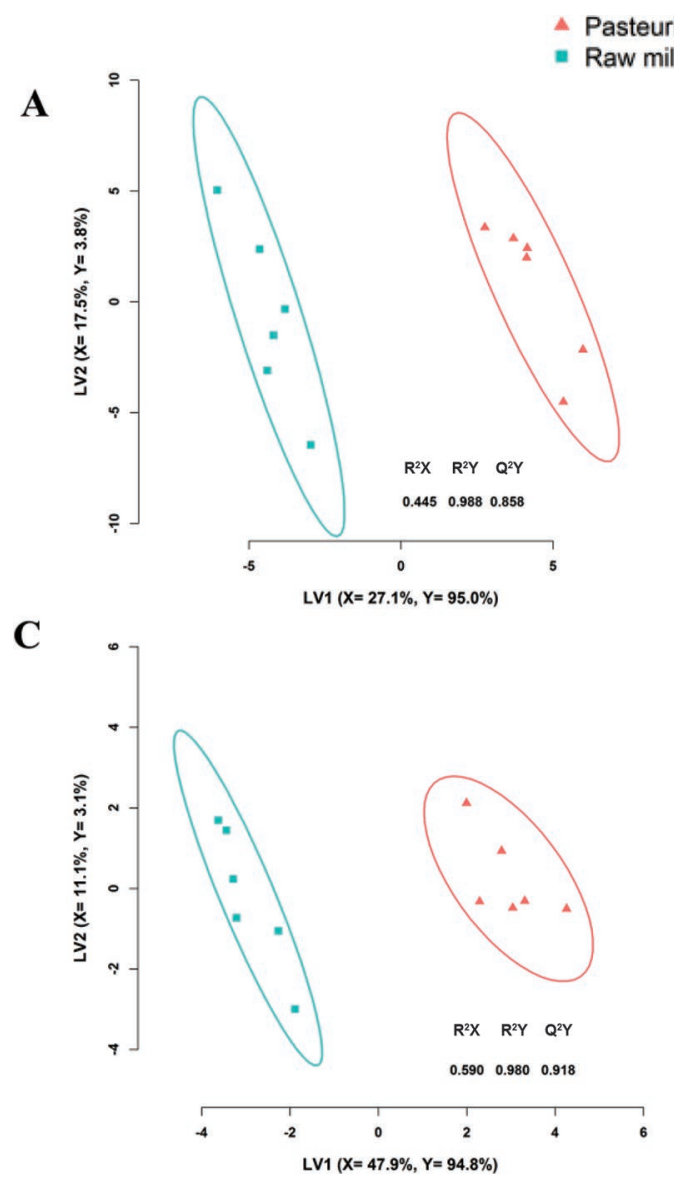
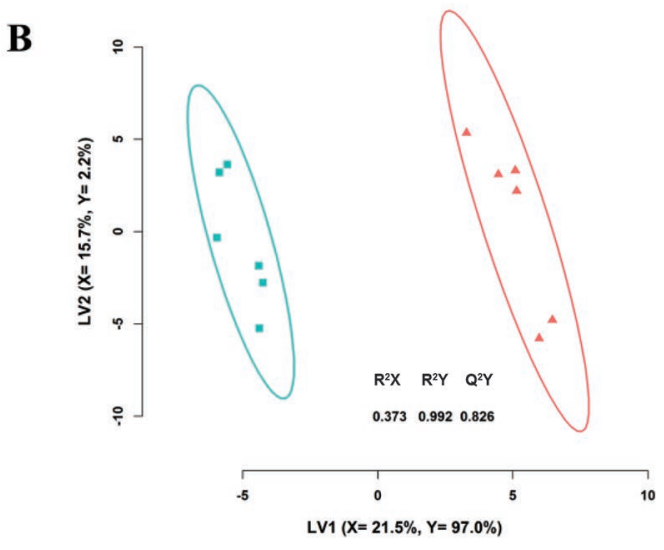

$\mathbf{D}$

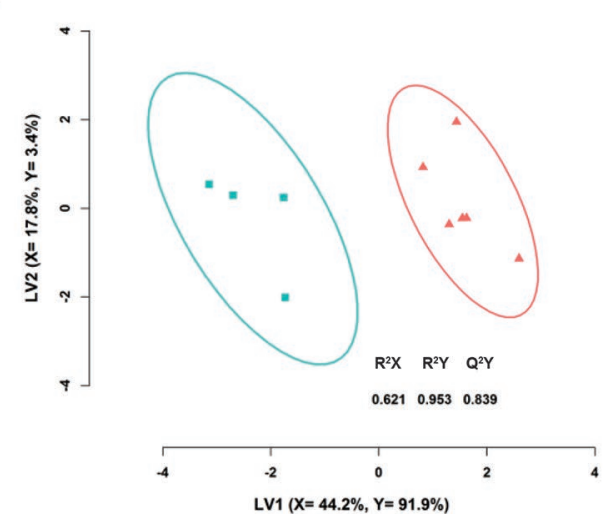

Figure 1. Partial least squares discriminant analysis score plots based on (A) ultraperformance liquid chromatography-quadrupole time-offlight MS (UPLC-QToF/MS) ESI ${ }^{+}$, (B) UPLC-QToF/MS ESI ${ }^{-}$, (C) ${ }^{1} \mathrm{H}$ nuclear magnetic resonance, and (D) GC-MS data of the milk samples before and after pasteurization processing. $\mathrm{ESI}=$ electrospray ionization; $\mathrm{LV}=$ latent variable. $\mathrm{R}^{2}$ and $\mathrm{Q}^{2}$ represented the explained variance and the predicted variation of the model, respectively. 

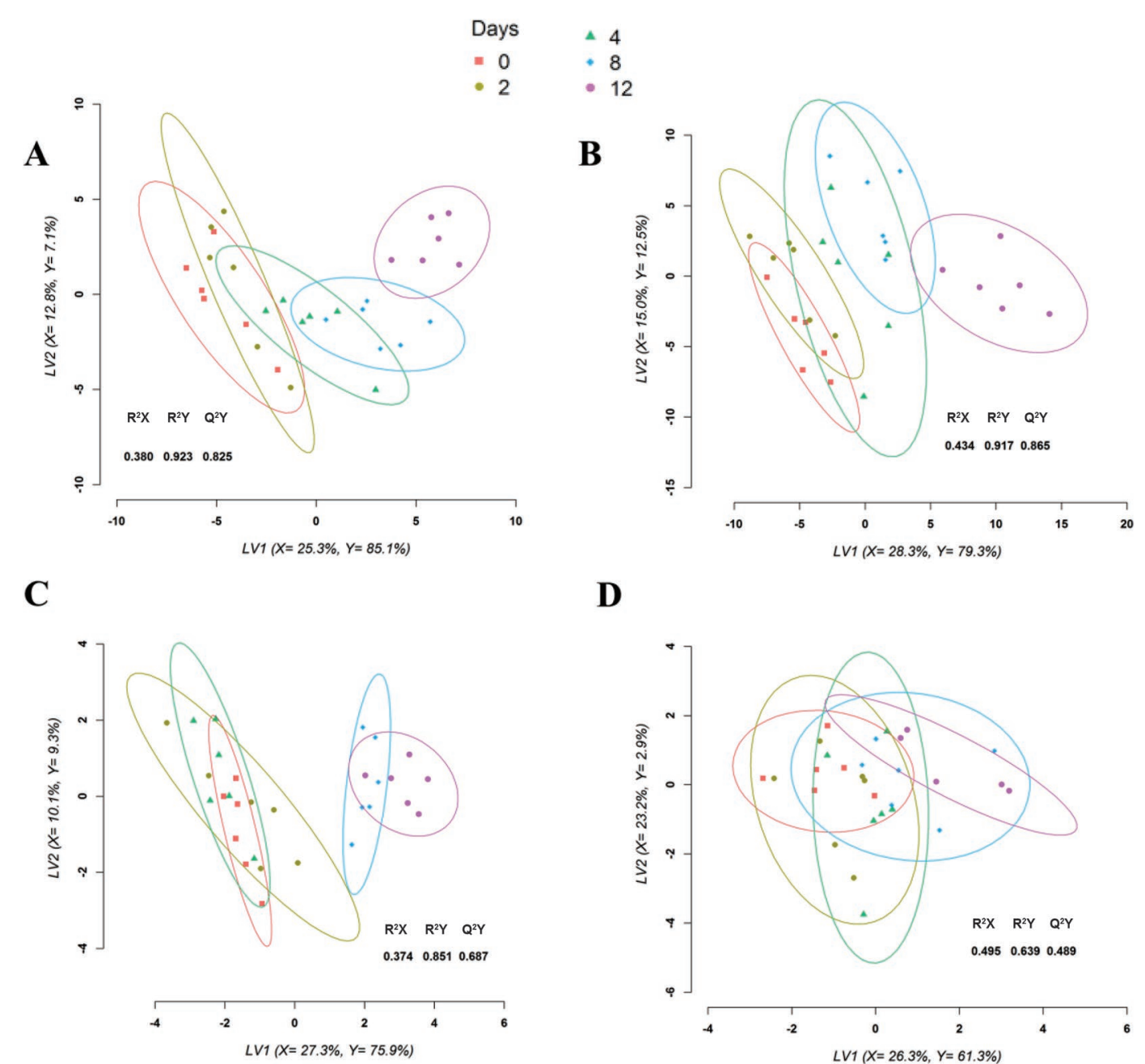

D

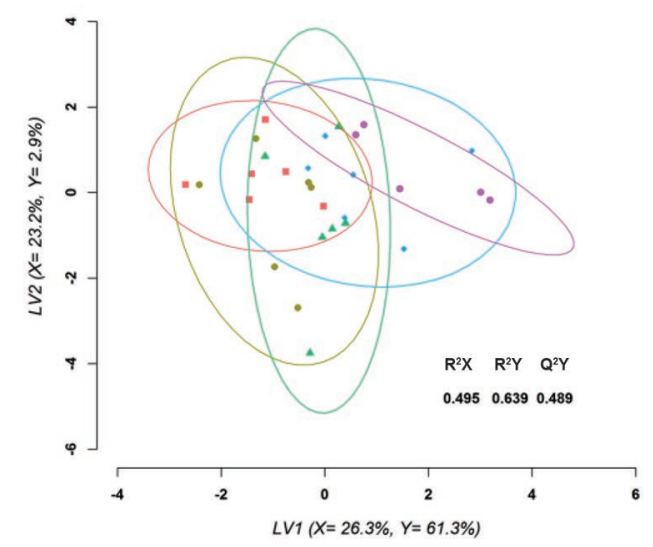

Figure 2. Partial least squares regression score plots based on (A) ultraperformance liquid chromatography-quadrupole time-of-flight MS (UPLC-QToF/MS) ESI ${ }^{+}$, (B) UPLC-QToF/MS ESI ${ }^{-}$, (C) ${ }^{1} \mathrm{H}$ nuclear magnetic resonance, and (D) GC-MS data of the pasteurized milk stored at $4^{\circ} \mathrm{C}$ for $0,2,4,8$, and $12 \mathrm{~d}$. ESI = electrospray ionization; $\mathrm{LV}=$ latent variable. $\mathrm{R}^{2}$ and $\mathrm{Q}^{2}$ represented the explained variance and the predicted variation of the model, respectively.

mained consistent during the first $4 \mathrm{~d}$ of storage. Obvious differences occurred from d 8 based on the data sets acquired by NMR and MS techniques (Figure $2 \mathrm{~A}-\mathrm{C}$ ). This result was in accordance with the microbial test result as the SPC on d 8 started to increase compared with that on d 0 (Supplemental Table S1, https://doi .org/10.3168/jds.2019-17512), though the SPC was still acceptable $(<20,000 \mathrm{cfu} / \mathrm{mL})$ until $\mathrm{d} 12$. However, the VOC in the pasteurized milk stored for different days showed only slight changes that were not large enough to separate the samples according to the length of storage (Figure 2D). Moreover, the $\mathrm{Q}^{2} \mathrm{Y}$ for the VOCbased PLSR model was also lower $(<0.5)$, representing a poorer prediction performance. Therefore, minor changes were observed in the score plot based on VOC (Figure 2D), though the SPC clearly increased in the pasteurized milk during refrigerated storage from d 0 to d 12. Rashid et al. (2019) reported that there was no variation between the concentration of the VOC and microbial populations, especially when the pasteurized milk was stored at $4^{\circ} \mathrm{C}$. The spoilage of a specific food substrate was recognized to be caused by the growth of a specific spoilage organism rather than the total microbial population (Marsili, 2000; Rashid et al., 2019).

To select the metabolites that change as a function of the storage, the VIP values of the metabolites based on PLSR models were extracted. The fold changes of the metabolites' levels under different storage periods compared with their initial values (d 0) were also calculated. The metabolites with a VIP value over 1.0 as well as the maximum of the fold changes larger than 2.0 (1.5 for VOC) were selected and are summarized in 
Table 1. Additionally, the Wilcoxon rank-sum test was applied to test the ANOVA of the selected metabolites. All the metabolites listed in Table 1 showed significant differences with $P<0.05$. The boxplots of the selected metabolites based on the detection techniques are illustrated in Supplemental Figure S5 (https://doi.org/ 10.3168/jds.2019-17512).

The variable selection procedure identified 24 metabolites that changed significantly as a function of storage time. These candidate biomarkers could be divided into 7 classes, including organic acids, AA and peptides, vitamins, carbohydrate deviates, carboxylic ester, ketones, and fatty acids. To clearly demonstrate the changes during the refrigerated storage of the pasteurized milk, bar plots of a representative of the selected metabolites, according to their classifications, are presented in Figure 3. As illustrated, the concentrations of most metabolites increased in pasteurized milk during the storage period. In addition, 2 ketones, detected by GC-MS, showed an increasing trend. However, the levels of pantothenic acid (vitamin $\mathrm{B}_{5}$ ) and butyrylcarnitine decreased along with the storage days.

\section{Milk Compositional Changes During Refrigerated Storage}

Milk is a protein-rich food, and it is important to evaluate its quality according to the contents of free AA. Some free AA were identified in this study, including alanine, leucine, methionine, glutamine, and glutamic acid, which had steady levels during both processing and refrigerated storage. The ion detected at 118.0858 $[\mathrm{M}+\mathrm{H}]^{+}$, with product ions 58.0649 and 59.0726 , was identified as glycine betaine, which belongs to the class of $\alpha$-AA. The betaine content increased slowly until d 12 , at which point it was approximately 2 times the level on $\mathrm{d} 0$. However, no related study reported on the changes in the betaine content in the pasteurized milk during refrigerated storage. Apart from the free AA, some ions detected, such as $344.2546\left([\mathrm{M}+\mathrm{H}]^{+}\right.$; retention time $=9.40 \mathrm{~min})$ and $340.2604\left([\mathrm{M}+\mathrm{H}]^{+}\right.$; retention time $=10.16 \mathrm{~min})$ were likely to be tripeptide, containing 3 AA (leucine, valine, or isoleucine). Specifically, the content of the detected ion $344.2546\left([\mathrm{M}+\mathrm{H}]^{+}\right)$, which was referred to be leucine-isoleucinele-valine, increased by almost 12-fold during the storage duration (Figure 3). Though some other ions identified as peptides were also detected in increasing amounts in the pasteurized milk during cold storage, the levels of these peptides were not stable (relative standard deviation $>20 \%$ ). The increase in peptides was probably caused by proteolysis due to the action of the plasmin and proteases from somatic cells or the thermoresis- tant proteolytic enzymes produced by psychrotrophic microorganisms (Santos et al., 2003; Milaneze et al., 2018). The proteolytic activity of milk has been found to remain after the pasteurization process $\left(76^{\circ} \mathrm{C}\right.$ for 30 s) and during cold storage $\left(0.5\right.$ and $6^{\circ} \mathrm{C}$ for $\left.61 \mathrm{~d}\right)$, as shown by the significant decrease of casein as a percentage of true protein (Santos et al., 2003). Additionally, Santos et al. (2003) found that the microbial growth had little effect on the total proteolysis when the SPC was $<30,000 \mathrm{cfu} / \mathrm{mL}$ by comparing the preserved and unpreserved pasteurized milk. Therefore, the increasing content of peptides in the pasteurized milk was mostly contributed by the native milk proteases during $12 \mathrm{~d}$ of storage with $\mathrm{SPC}<20,000 \mathrm{cfu} / \mathrm{mL}$.

Organic acids provide characteristic taste to food, and their acidic nature helps to prevent milk spoilage. In the present work, the change in the organic acid contents during vat pasteurization was not significant. However, the amounts of some organic acids, such as succinic acid, ribonic acid (165.0401 $\left.[\mathrm{M}-\mathrm{H}]^{-}\right)$, and galactonic acid/gluconic acid (195.0513 [M-H] ${ }^{-}$), increased during refrigerated storage. The increase in the amounts of succinic acid could be due to the oxidation of fatty acids during heat treatment (Nishimura et al., 2015). This increasing trend was pronounced at the late stage of refrigerated storage. Another increasing ion detected was $171.0066\left([\mathrm{M}-\mathrm{H}]^{-}\right)$, which was identified as glycerol 3-phosphate, a chemical intermediate in the glycolysis metabolic pathway. Another ion detected with an obvious increasing trend during refrigerated storage was $158.1178\left([\mathrm{M}+\mathrm{H}]^{+}\right.$; retention time $=1.87$ min), which was most likely an organic acid considering the retention time. However, it was challenging to confirm the identity without the aid of product ions. On the contrary, butyrylcarnitine, the L-carnitine butyryl ester, showed a decreasing trend during the storage period of pasteurized milk.

Milk is also a good source for water-soluble vitamins, such as riboflavin (vitamin $\mathrm{B}_{2}$ ), ascorbic acid (vitamin $\mathrm{C}$ ), and pantothenic acid (vitamin $\mathrm{B}_{5}$ ). It was reported that water-soluble vitamins are more sensitive to heat treatment in general compared with fat-soluble vitamins (Bendicho et al., 2002). In the present work, among the water-soluble vitamins, the level of riboflavin (vitamin $\mathrm{B}_{2}$ ) and cobalamin (vitamin $\mathrm{B}_{12}$ ) was thermostable without significant change during the pasteurization process and subsequent refrigerated storage. This result was consistent with previous reports that no marked loss of vitamins due to the pasteurization process $\left(75^{\circ} \mathrm{C}\right.$ for $16 \mathrm{~s})$ or heat treatment $\left(63^{\circ} \mathrm{C}\right.$ for $\left.30 \mathrm{~min}\right)$ was found (Andersson and Oste, 1994; Bendicho et al., 2002). In addition, no general changes in cobalamin content occurred during domestic refrigerator storage in $7 \mathrm{~d}$ 


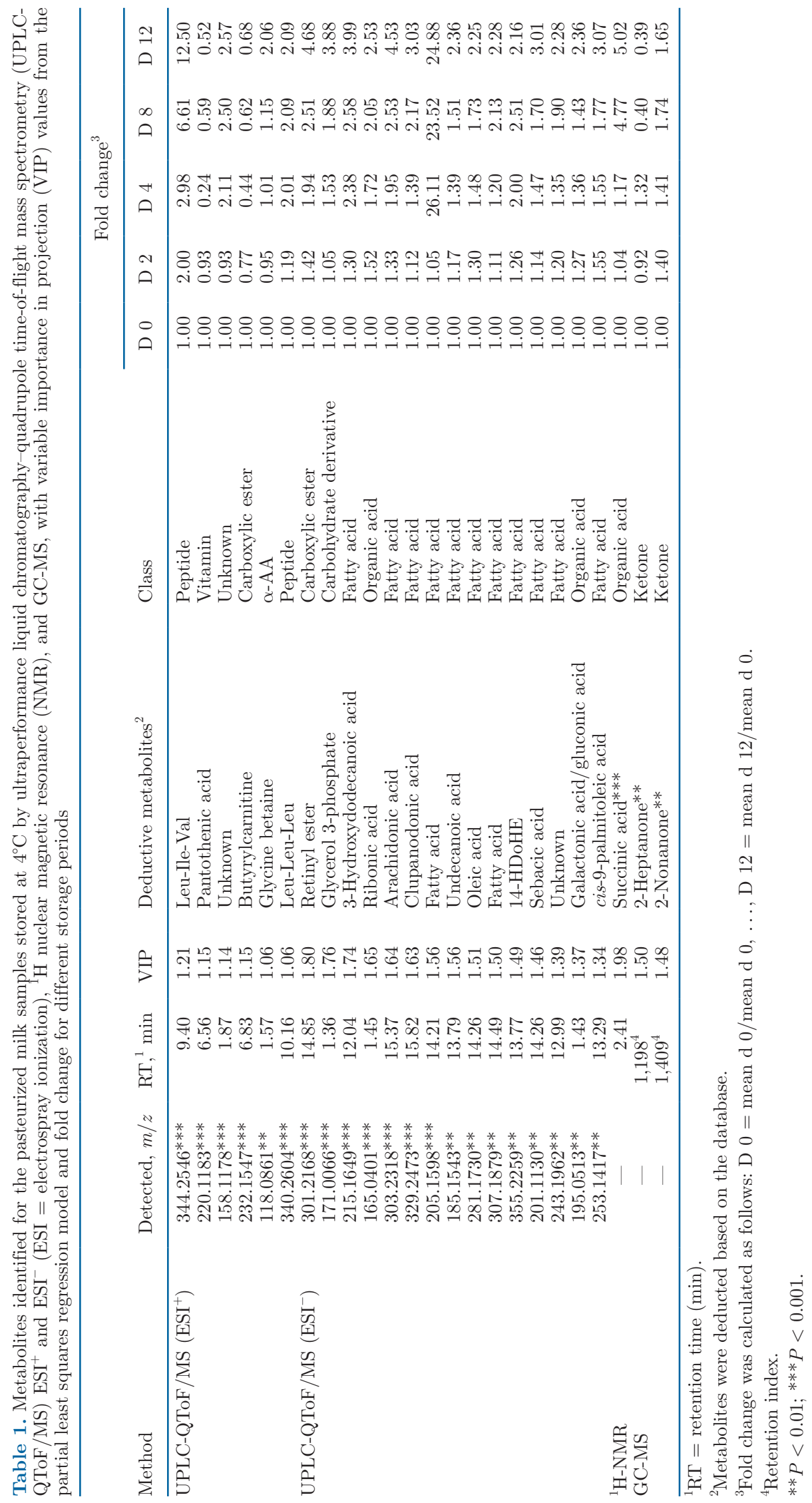


(Andersson and Oste, 1994). The concentration of pantothenic acid (vitamin $\mathrm{B}_{5}$ ) in pasteurized milk was not influenced by the heat treatment but decreased during refrigerated storage in this study (Figure 3). This result was in line with previous studies where no significant change was observed in the content of pantothenic acid in the pasteurized milk $\left(62.5^{\circ} \mathrm{C}\right.$ for $\left.30 \mathrm{~min}\right)$ compared with that in the raw milk (Goldsmith et al., 1983). The level of pantothenic acid was stable in the pasteurized milk $\left(62.5^{\circ} \mathrm{C}\right.$ for $30 \mathrm{~min}$ ) stored at $-25^{\circ} \mathrm{C}$ (Friend et al., 1983). However, no study on the stability of panto- thenic acid in pasteurized milk during cold storage has been reported.

No significant difference was found for the pasteurization influence on milk fatty acid profiles. However, the amounts of free fatty acids increased during the refrigerated storage of the pasteurized milk. As shown in Figure 3, the levels of the fatty acids, such as arachidonic acid $\left(303.2318\left[\mathrm{M}^{-}\right]\right)$, oleic acid $\left(281.1730\left[\mathrm{M}^{-}\right]\right)$, and undecanoic acid $\left(185.1543\left[\mathrm{M}^{-}\right]\right)$, showed an increasing trend, especially from d 8 to 12 . Our results were in accordance with a previous report (Santos et

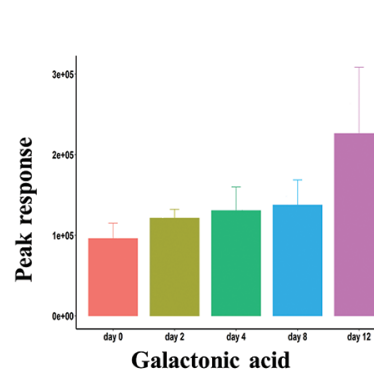

Organic acid

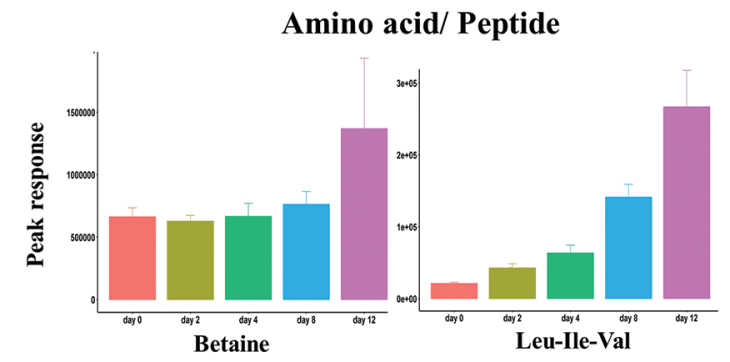

Carbohydrate derivative
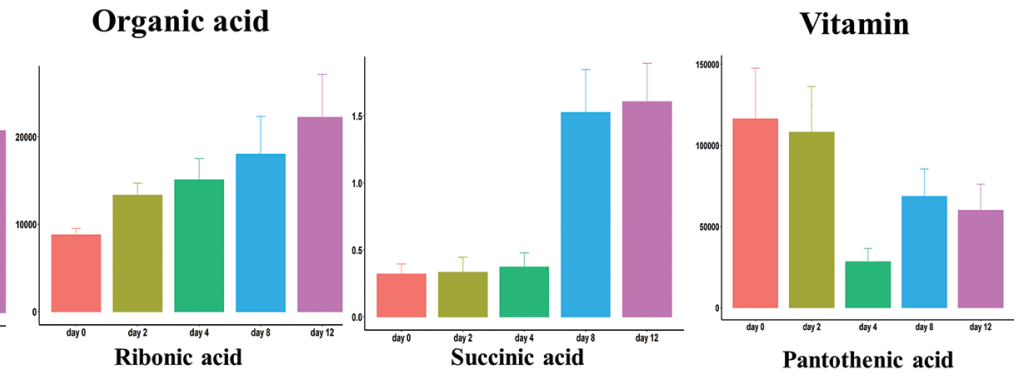

Carboxylic ester
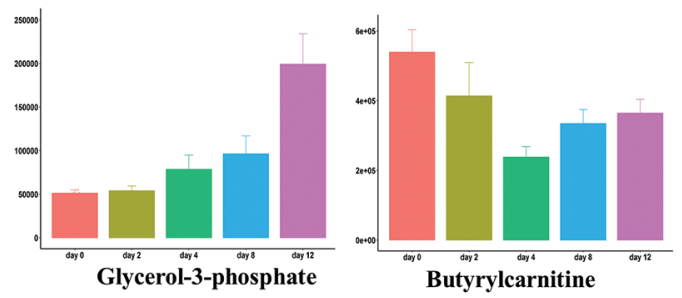

Ketone

Fatty acid
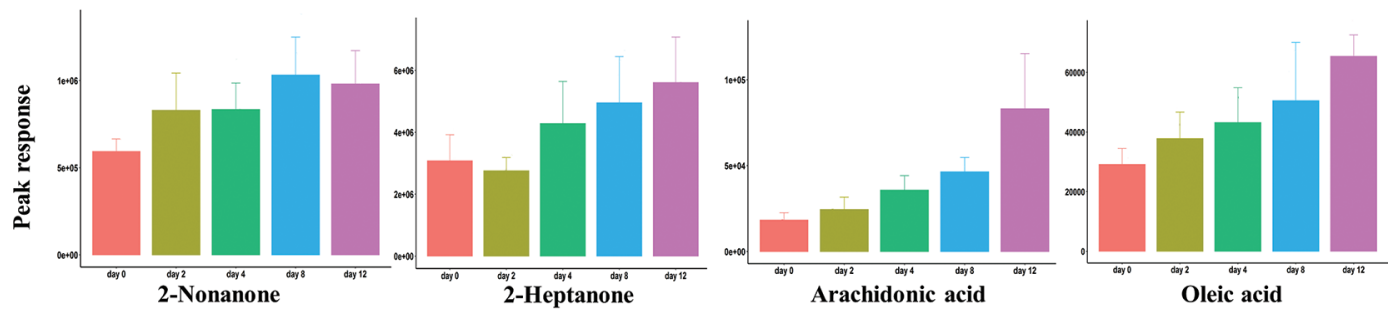

Fatty acid
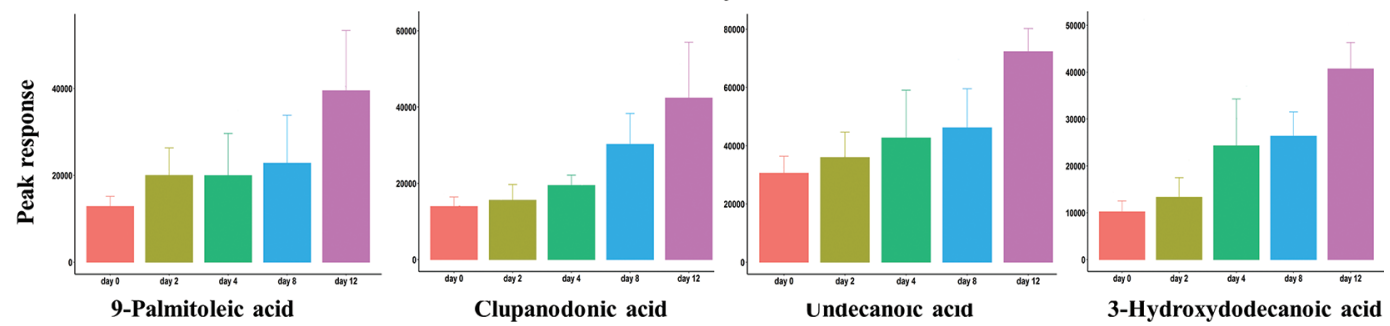

Figure 3. Bar plots of the changed metabolites in the pasteurized milk at $4^{\circ} \mathrm{C}$ during the storage period $(0-12 \mathrm{~d})$. Error bars show $\mathrm{SD}$ within the group. 
al., 2003). The increasing free fatty acids in homogenized, pasteurized milk $\left(76^{\circ} \mathrm{C}\right.$ for $\left.30 \mathrm{~s}\right)$ during cold storage $\left(0.5\right.$ and $\left.6^{\circ} \mathrm{C}\right)$ were found to be significantly affected by storage temperature, time, and SCC in the study by Santos et al. (2003). The increasing of the fatty acids was probably caused by milk fat lipolysis due to the action of milk lipases that survived pasteurization. Lipoprotein lipase was regarded to account for most, if not all, of the lipolysis activity in milk (Deeth, 2006). Though the milk pasteurization process could inactivate most of the lipoprotein lipase, it could not be fully inactivated until the milk was treated with more severe conditions $\left(79^{\circ} \mathrm{C}\right.$ for $\left.20 \mathrm{~s}\right)$ as suggested (Shipe and Senyk, 1981). Additionally, the lipases from somatic cells may contribute significantly to lipolysis of milk during cold storage (Azzara and Dimick, 1985). Therefore, the lipoprotein lipase that survived the vat pasteurization process $\left(63^{\circ} \mathrm{C}\right.$ for $\left.30 \mathrm{~min}\right)$ or the lipase from somatic cells would cause lipolysis of the milk fat, hence increasing fatty acid levels. This is important for milk quality because the higher the free fatty acid level, the more likely we are to detect the rancid off-flavors in the whole milk (Fromm and Boor, 2004; Lu et al., 2013). Therefore, these increasing levels of free fatty acids were relevant to the shelf life of the pasteurized milk, which could be used to indicate the end of the safe storage period.

Volatile organic compounds were reported to be related to the heat treatment and shelf life of milk, and some VOC are responsible for the off-flavor in bovine milk (Gandy et al., 2008). The most abundant class of VOC in milk is the ketone family, which contributes to the milk flavor (Contarini et al., 1997). In our study, the level of 2-nonanone more than doubled and the content of 2-butanone decreased in the pasteurized milk compared with the raw milk (Supplemental Table S3, https: //doi.org/10.3168/jds.2019-17512). The increase of the 2 -nonanone could be due to heat-induced $\beta$-oxidation of SFA followed by decarboxylation, the rate of which would be related to the pasteurization temperature (Contarini et al., 1997; Chugh et al., 2014). Faulkner et al. (2018) similarly reported that the 2-nonanone was found to be present in pasteurized milk but absent in some raw milk. They also found that the content of 2-butanone had a greater association with raw milk compared with pasteurized milk, indicating the direct pasteurization effect on 2-butanone (Faulkner et al., 2018). In their study, the average content of 2-butanone in the pasteurized milk was lower than that in raw milk. The content of 2-butanone in UHT milk was found to be lower than that in pasteurized milk, which was attributed to the stripping of the VOC during flash cooling (Contarini et al., 1997). However, the forma- tion of 2-butanone was found to be different from other ketones after the heating treatment, indicating that it was likely formed by a different mechanism that needed to be further studied (Langler, 1964). In addition, the main variation of the VOC in pasteurized milk during the cold-storage period was the methyl ketones, which could be due to the lipid oxidation. Specifically, the levels of 2-nonanone and 2-heptanone were observed to have increased as a function of storage days, which was in accordance with a previous report (Valero et al., 2001).

\section{CONCLUSIONS}

Minor changes in the metabolome were caused by the vat pasteurization process of milk based on the PLS-DA model built from the data acquired from ${ }^{1} \mathrm{H}-$ NMR and UPLC-QToF/MS and headspace GC-MS techniques. This indicates that vat pasteurization was an efficient and mild way to treat milk with minimal effects on the nutritional compounds. During refrigerated storage, the concentrations of some metabolites, such as pantothenic acid and butyrylcarnitine, decreased by half, whereas other metabolites, including some fatty acids, succinic acid, glycine, betaine, glycerol 3-phosphate, and some tripeptides, increased by more than 2 . In addition, the concentration of some volatile compounds, such as 2-nonanone and 2-heptanone, showed an increasing trend during the last days of the storage period. These selected metabolites (Table 1), especially at the last stage of the storage period, could be used as potential biomarkers to track the storage conditions of pasteurized milk. The identity of these selected biomarkers, from untargeted metabolomics, could be further verified using pure standards. Once identified, targeted analysis could be explored to quantify the selected potential markers. Finally, these confirmed biomarkers could be used for a targeted kinetic study to establish models for tracking changes in milk shelf life.

\section{ACKNOWLEDGMENTS}

This work was supported by MBIE NZ-China Grant: Integrated Tracing Technologies for Dairy Products (grant number UOOX1501) and University of Otago (Dunedin, New Zealand) PhD Scholarship to Dan Zhu. The authors thank the owner of Holy Cow Farm (Dunedin, New Zealand) for their cooperation with the sample collection. We also thank Michelle Leus and Michelle Petrie from the Department of Food Science, University of Otago, for their kind help with gas chromatography-mass spectrometry and microbial testing. The authors have not stated any conflicts of interest. 


\section{REFERENCES}

Andersson, I., and R. Oste. 1994. Nutritional quality of pasteurized milk. Vitamin $\mathrm{B}_{12}$, folate and ascorbic acid content during storage. Int. Dairy J. 4:161-172. https://doi.org/10.1016/0958 -6946(94)90066-3.

Azzara, C. D., and P. S. Dimick. 1985. Lipoprotein lipase activity of milk from cows with prolonged subclinical mastitis. J. Dairy Sci. 68:3171-3175. https://doi.org/10.3168/jds.S0022-0302(85)81223 $-6$.

Bendicho, S., A. Espachs, J. Arántegui, and O. Martín. 2002. Effect of high intensity pulsed electric fields and heat treatments on vitamins of milk. J. Dairy Res. 69:113-123. https://doi.org/10.1017/ S0022029901005258.

Berkeley Wellness. 2014. Ask the experts: Low temperature pasteurized milk. Accessed Dec. 12, 2014. https://www.berkeleywellness.com/ healthy-eating/food-safety/article/low-temperature-pasteurized -milk.

Borad, S. G., A. Kumar, and A. K. Singh. 2017. Effect of processing on nutritive values of milk protein. Crit. Rev. Food Sci. Nutr. 57:3690-3702. https://doi.org/10.1080/10408398.2016.1160361.

Cappozzo, J. C., T. Koutchma, and G. Barnes. 2015. Chemical characterization of milk after treatment with thermal (HTST and UHT) and nonthermal (turbulent flow ultraviolet) processing technologies. J. Dairy Sci. 98:5068-5079. https://doi.org/10.3168/jds.2014 -9190 .

Chugh, A., D. Khanal, M. Walkling-Ribeiro, M. Corredig, L. Duizer, and M. W. Griffiths. 2014. Change in color and volatile composition of skim milk processed with pulsed electric field and microfiltration treatments or heat pasteurization. Foods 3:250-268. https: //doi.org/10.3390/foods3020250.

Contarini, G., M. Povolo, R. Leardi, and P. M. Toppino. 1997. Influence of heat treatment on the volatile compounds of milk. J. Agric. Food Chem. 45:3171-3177. https://doi.org/10.1021/jf960849s.

Deeth, H. C. 2006. Lipoprotein lipase and lipolysis in milk. Int. Dairy J. $16: 555-562$.

Di Guida, R., J. Engel, J. W. Allwood, R. J. M. Weber, M. R. Jones, U. Sommer, M. R. Viant, and W. B. Dunn. 2016. Non-targeted UHPLC-MS metabolomic data processing methods: A comparative investigation of normalisation, missing value imputation, transformation and scaling. Metabolomics 12:93.

Faulkner, H., T. F. O'Callaghan, S. McAuliffe, D. Hennessy, C. Stanton, M. G. O'Sullivan, J. P. Kerry, and K. N. Kilcawley. 2018. Effect of different forage types on the volatile and sensory properties of bovine milk. J. Dairy Sci. 101:1034-1047. https://doi.org/10 $.3168 /$ jds.2017-13141.

Friend, B. A., K. M. Shahani, C. A. Long, and E. N. Agel. 1983. Evaluation of freeze-drying, pasteurization, high-temperature heating and storage on selected enzymes, B-vitamins and lipids of mature human milk. J. Food Prot. 46:330-334. https://doi.org/10.4315/ 0362-028X-46.4.330.

Fromm, H. I., and K. J. Boor. 2004. Characterization of pasteurized fluid milk shelf-life attributes. J. Food Sci. 69:M207-M214. https: //doi.org/10.1111/j.1365-2621.2004.tb09889.x.

Gandy, A. L., M. W. Schilling, P. C. Coggins, C. H. White, Y. Yoon, and V. V. Kamadia. 2008. The effect of pasteurization temperature on consumer acceptability, sensory characteristics, volatile compound composition, and shelf-life of fluid milk. J. Dairy Sci. 91:1769-1777. https://doi.org/10.3168/jds.2007-0833.

Goldsmith, S. J., R. R. Eitenmiller, R. T. Toledo, and H. M. Barnhart. 1983. Effects of processing and storage on the water-soluble vitamin content of human milk. J. Food Sci. 48:994-995. https://doi .org/10.1111/j.1365-2621.1983.tb14951.x.

Kim, S., J. Kim, E. J. Yun, and K. H. Kim. 2016. Food metabolomics: From farm to human. Curr. Opin. Biotechnol. 37:16-23. https:// doi.org/10.1016/j.copbio.2015.09.004.

Krishnamurthy, K. 2013. CRAFT (complete reduction to amplitude frequency table)-Robust and time-efficient Bayesian approach for quantitative mixture analysis by NMR. Magn. Reson. Chem. $51: 821-829$.
Langler, J. E. 1964. Factors influencing methyl ketone formation in milk fat. MS Thesis. Department of Food Science and Technology, Oregon State University, Corvallis.

Lu, M., Y. Shiau, J. Wong, R. Lin, H. Kravis, T. Blackmon, T. Pakzad, T. Jen, A. Cheng, J. Chang, E. Ong, N. Sarfaraz, and N. S. Wang. 2013. Milk spoilage: Methods and practices of detecting milk quality. Food Nutr. Sci. 4:113-123. https://doi.org/10.4236/ fns.2013.47A014.

Lucey, J. A. 2015. Raw milk consumption: Risks and benefits. Nutr. Today 50:189-193. https://doi.org/10.1097/NT.0000000000000108.

Macdonald, L. E., J. Brett, D. Kelton, S. E. Majowicz, K. Snedeker, and J. M. Sargeant. 2011. A systematic review and meta-analysis of the effects of pasteurization on milk vitamins, and evidence for raw milk consumption and other health-related outcomes. J. Food Prot. 74:1814-1832. https://doi.org/10.4315/0362-028X.JFP $-10-269$.

Marsili, R. T. 2000. Shelf-life prediction of processed milk by solidphase microextraction, mass spectrometry, and multivariate analysis. J. Agric. Food Chem. 48:3470-3475. https://doi.org/10.1021/ jf000177c

Martin, N. H., K. J. Boor, and M. Wiedmann. 2018. Symposium review: Effect of post-pasteurization contamination on fluid milk quality. J. Dairy Sci. 101:861-870. https://doi.org/10.3168/jds .2017-13339.

Meunier-Goddik, L., and S. Sandra. 2011. Liquid milk products: Pasteurized milk. Pages 274-279 in Encyclopedia of Dairy Sciences. 2nd ed. Vol. 3. J. W. Fuquay, ed. Elsevier, London, UK.

Meunier-Goddik, L., and S. Sandra. 2016. Liquid milk products: Pasteurized milk. In Reference Module in Food Science. Elsevier, London, UK.

Milaneze, H. S., L. S. Silva, L. B. M. Kottwitz, M. A. Zambom, L. M. Fonseca, A. T. B. Guimarães, and M. S. S. Pozza. 2018. Microbiological, chemical, physical, and proteolytic activities of raw milk after thermal processing. Arq. Bras. Med. Vet. Zootec. 70:16251632. https://doi.org/10.1590/1678-4162-9662.

Nicholson, J. K., J. C. Lindon, and E. Holmes. 1999. "Metabonomics": Understanding the metabolic responses of living systems to pathophysiological stimuli via multivariate statistical analysis of biological NMR spectroscopic data. Xenobiotica 29:1181-1189. https:// doi.org/10.1080/004982599238047.

Nishimura, J., S. Makino, K. Kimura, E. Isogai, and T. Saito. 2015. Influence of different sterilization conditions on the growth and exopolysaccharide of Streptococcus thermophilus and co-cultivation with Lactobacillus delbrueckii subsp. bulgaricus OLL1073R-1. Adv. Microbiol. 5:760-767. https://doi.org/10.4236/aim.2015.511080.

Ott, A., L. B. Fay, and A. Chaintreau. 1997. Determination and origin of the aroma impact compounds of yogurt flavor. J. Agric. Food Chem. 45:850-858. https://doi.org/10.1021/jf960508e.

R Core Team. 2019. R: A Language and Environment for Statistical Computing. R Foundation for Statistical Computing, Vienna, Austria.

Rankin, S. A., R. L. Bradley, G. Miller, and K. B. Mildenhall. 2017. A 100-year review: A century of dairy processing advancementsPasteurization, cleaning and sanitation, and sanitary equipment design. J. Dairy Sci. 100:9903-9915. https://doi.org/10.3168/jds 2017-13187.

Rashid, A., I. Javed, B. Rasco, S. Sablani, M. Ayaz, M. Ali, M. Abdullah, M. Imran, T. Gondal, M. Afzal, M. Atif, B. Salehi, C. Rodrigues, J. Sharifi-Rad, and N. Martins. 2019. Measurement of off-flavoring volatile compounds and microbial load as a probable marker for keeping quality of pasteurized milk. Appl. Sci. (Basel) 9:959. https://doi.org/10.3390/app9050959.

Rodríguez-Alcalá, L. M., L. Alonso, and J. Fontecha. 2014. Stability of fatty acid composition after thermal, high pressure, and microwave processing of cow milk as affected by polyunsaturated fatty acid concentration. J. Dairy Sci. 97:7307-7315. https://doi.org/10 .3168/jds.2013-7849.

Sakkas, L., A. Moutafi, E. Moschopoulou, and G. Moatsou. 2014. Assessment of heat treatment of various types of milk. Food Chem. 159:293-301. https://doi.org/10.1016/j.foodchem.2014.03.020. 
Santos, M. V., Y. Ma, and D. M. Barbano. 2003. Effect of somatic cell count on proteolysis and lipolysis in pasteurized fluid milk during shelf-life storage. J. Dairy Sci. 86:2491-2503. https://doi.org/10 .3168/jds.S0022-0302(03)73843-0.

Shipe, W. F., and G. F. Senyk. 1981. Effects of processing conditions on lipolysis in milk. J. Dairy Sci. 64:2146-2149. https://doi.org/10 $.3168 /$ jds.S0022-0302(81)82821-4.

Souza, C. F. V., J. M. Pestana, A. Gennari, B. W. Monteiro, and D. N. Lehn. 2015. Effects of pasteurization and ultra-high temperature processes on proximate composition and fatty acid profile in bovine milk. Am. J. Food Technol. 10:265-272. https://doi.org/10 .3923/ajft.2015.265.272.

Valero, E., M. Villamiel, B. Miralles, J. Sanz, and I. Martínez-Castro. 2001. Changes in flavour and volatile components during storage of whole and skimmed UHT milk. Food Chem. 72:51-58. https:// doi.org/10.1016/S0308-8146(00)00203-X.

Wang, C., X. Lou, and J. Wang. 2016. Fatty acid composition and fat stability of raw milk and pasteurized milk from Laoshan goats. J. Agric. Sci. 8:149. https://doi.org/10.5539/jas.v8n6p149.

Watts, S. 2016. A mini review on technique of milk pasteurization. J Pharmacogn. Phytochemistry 5:99-101.

Shapiro, S. S., and M. B. Wilk. 1965. An analysis of variance test for normality (complete samples). Biometrika 52:591-611. https://doi .org/10.1093/biomet/52.3-4.591.

Wishart, D. S. 2008. Metabolomics: Applications to food science and nutrition research. Trends Food Sci. Technol. 19:482-493. https:// doi.org/10.1016/j.tifs.2008.03.003.
Yi, J., B. T. Kebede, T. Grauwet, A. Van Loey, X. Hu, and M. Hendrickx. 2016. A multivariate approach into physicochemical, biochemical and aromatic quality changes of purée based on Hayward kiwifruit during the final phase of ripening. Postharvest Biol. Technol. 117:206-216. https://doi.org/10.1016/j.postharvbio.2016 .03.007.

Yi, J., B. T. Kebede, D. N. Hai Dang, C. Buvé, T. Grauwet, A. Van Loey, X. Hu, and M. Hendrickx. 2017. Quality change during highpressure processing and thermal processing of cloudy apple juice. Lebensm. Wiss. Technol. 75:85-92. https://doi.org/10.1016/j.lwt .2016.08.041.

Zhang, Y. D., P. Li, N. Zheng, Z. W. Jia, N. Meruva, A. Ladak, G. Cleland, F. Wen, S. L. Li, S. G. Zhao, and J. Q. Wang. 2018. A metabolomics approach to characterize raw, pasteurized, and ultra-high temperature milk using ultra-performance liquid chromatography-quadrupole time-of-flight mass spectrometry and multivariate data analysis. J. Dairy Sci. 101:9630-9636. https:// doi.org/10.3168/jds.2018-14441.

\section{ORCIDS}

Dan Zhu (ㄱ https://orcid.org/0000-0002-6136-1788

Biniam Kebede (ㄴ) https://orcid.org/0000-0001-5774-9539

Kiri McComb ๑ https://orcid.org/0000-0001-8891-6643

Russell Frew 나 https://orcid.org/0000-0002-6138-2116 